\title{
Flexible Learning in Computer Science
}

\author{
Dr Neil Andrew Gordon \\ Computer Science, University of Hull, Cottingham Road, Hull, HU6 7RX \\ Corresponding Author: n.a.gordon@hull.ac.uk
}

Keywords: Computer Based Instruction; Adaptive eLearning; Flexible Pedagogy

\section{Abstract}

This paper outlines the concept of Flexible Pedagogy and how it can assist in addressing some of the issues facing STEM disciplines in general, and Computer Science in particular. The paper considers what flexible pedagogy is and how technologies developed by Computer Science can enable flexibility. It then describes some of the issues facing STEM education, with a particular focus on Computer Science education in Higher Education. Finally, it considers how flexible approaches to teaching and learning are particularly pertinent to the issues faced in Computer Science and future opportunities.

\section{Introduction}

Higher (tertiary) education (H.E.) continues to evolve across the world, with continued growth in terms of the overall numbers or proportion entering H.E.. This can also mean that the profile of the cohort widens, with more diverse backgrounds, and prior educational experience and attainment, creating new challenges in this revolution (Altbach et al, 2009).

Within H.E. in the U.K., an emerging issue has been the requirement to respond to student expectations and needs (Universities UK, 2016). One particular aspect is that of student choice. With growing numbers of part-time and non-traditional learners, an approach to address this has been through enabling flexibility within education, i.e. Flexible Pedagogy.

\section{Flexible Pedagogy}

Flexible pedagogy may be thought of as an approach to developing teaching and learning where student choice is paramount (Higher Education Academy, 2013). Here, choice can be thought of in three dimensions (Figure 1), namely the mode, pace and place of learning.

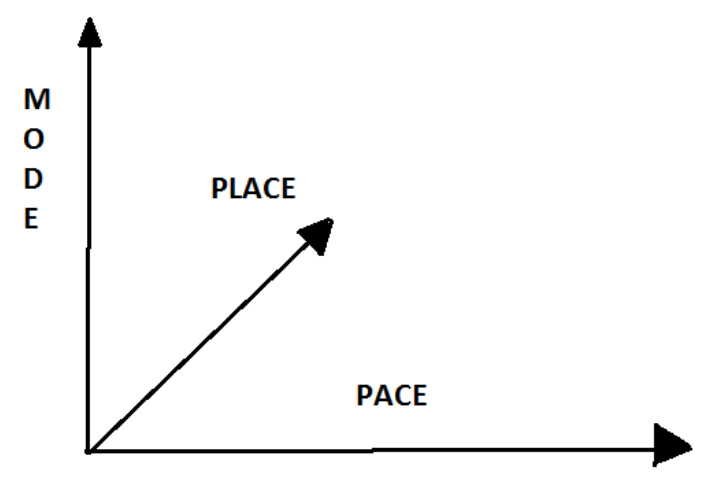

Figure 1 The 3 Dimensions of Flexibility

- Mode: considers the how students learn. This may be through enabling different forms of learning (e.g. supporting the visual learner, or those with specific learning needs).

- Pace: refers to time, both the when of learning, and how fast the learner progresses;

- Place: is about where learning and assessment happen, which may be the classroom, at home or work, or outside.

In practical terms, flexibility must be balanced against other needs, in particular given limitations of resource, of cost and of the nature 
Flexible Learning in Computer Science

of disciplines. But technology can assist with some of the practicalities as described next.

\section{Technology and Flexibility}

As considered in Gordon (2014), technology can enable flexibility as it helps to addresses issues of personalisation and scale that are typical features of, and challenges for, higher education. Some of these technologies are established, while many are still under development as they apply innovations and techniques from Computer Science. Others are emerging as Computer Science offers new solutions. Example are:

- Mode: learning environments - such as Virtual Learning Environments, and Course Management Systems - can facilitate the offering of a range of learning resources to students to enable different types of learning and potentially improve the student experience (Cassidy, 2016). This may supplement traditional teaching - for example, through blended approaches (O'Byme and Pytash, 2015) - or replace it entirely with a move to clicks-only education (Pathak and Pathak, 2010).

- Pace: computer mediated learning means that the learner can control the rate of delivery, for example through playback of video capture or by choosing when to take assessments (Verkroost et al, 2008);

- Place: internet access to resources, live or recorded streaming of sessions, virtual conferences, workshops and labs can all enable some choice. Moreover, mobile devices can truly enable - at least some - learning in any location (Sarrab et al, 2012).

\section{Computer Mediated Instruction}

One of the benefits of modern computer learning environments is that it is now viable to set up pathways of resources that can be controlled by the system. In combination with some student choice, this can enable pathways of learning (figure 2) with materials being chosen by students or the system itself, though with the system controlling (through gateways or constraints) access to later content dependent on suitable evidence of mastery or engagement.

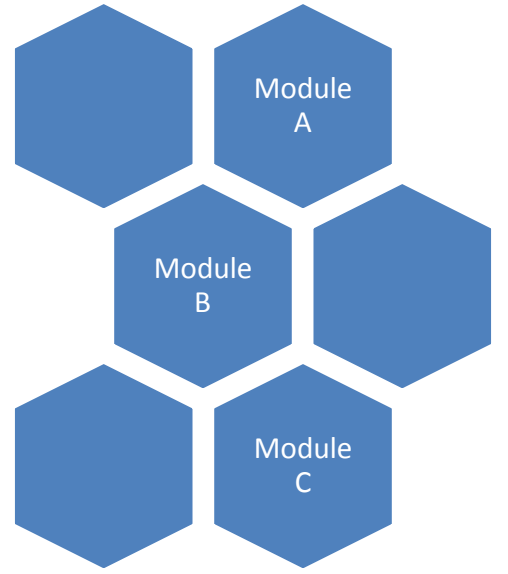

Figure 2 Learning Pathways

Such collections of material and pathways may be configured in a variety of ways, and this approach to personalised and adaptive learning (Wen et al, 2012) may ultimately enable - with appropriate resources and support -students to truly learn anywhere, anytime and anyhow they wish.

The benefits of this for teacher and learners are varied, and reflect their different needs. For teachers, benefits include:

- Allowing scalable solutions: material can be delivered to large cohorts in a controlled way;

- Technology can enable novel approaches: variety of types of content, different approaches to assessment;

- The automation of various aspects of teaching, from assessment, through attendance monitoring and measuring engagement, through to generating bespoke data sets for assessments to preclude plagiarism or collusion.

The use of these learning technologies here encourages a shift for the teacher as manager of the educational process, rather than the primary deliverer. Of course, this shift in role for the teacher does not necessarily save time, though it can increase efficiency in allowing for larger cohorts, more special support and potentially better results.

For learners, some of the benefits are:

- Support for differing learning styles, and presenting ideas in a number of ways; 
- The choices and flexibility can support students' different lifestyle needs, e.g. for those with work or family commitments;

- The learning experience becomes personalised to their needs.

Such learning pathways and personalised approaches utilise intelligent systems and learning analytics - a particular application of data mining. There are opportunities for further develop as big data techniques and semantic web can allow new and novel analysis of learners' behaviours, of identifying their needs (big data) and of locating and supplying relevant personalised material (semantic web).

\section{Challenges in STEM education}

All students - regardless of discipline - face a number of challenges as they travel through their higher education journey. Some of the key challenges are:

- Understanding what they are expected and required to do and what they need to do;

- Actively engaging with their learning;

- Getting help and assistance when they need it;

- Completing their intended course.

Beyond these general issues in learning, UK STEM provision was highlighted in 2015, because of concerns about the employability of STEM graduates, with the statement that whilst STEM disciplines are key to the economy, "some STEM subjects do not have a strong graduate employment record" (HEFCE, 2015). Computer Science was further highlighted within STEM as having the worst employability rating. With accreditation particularly relevant to employability, this led to reports on employability and accreditation within STEM generally and Computer Science in particular, this latter considered in Shadbolt (2015).

Complementing the above HEFCE reports, an earlier publication by the Higher Education Academy (Woodfield, 2014) reported on attainment and retention across all subjects. This report highlighted concerns within several subjects, in particularthe fact that the majority STEM subjects suffered from higher than average rates of academic failure (retention), with 4 out of 9 STEM subjects exhibiting lower levels of students with upper degrees (i.e. attainment). Computer Science was highlighted in particular, with the second worst record overall for attainment, and the worst record for retention. This led to a follow up reports on several disciplines, with (Gordon, 2015) analysing these problems for Computer Science, and identifying a number of potential solutions, some of which follow below.

\section{The Challenge of Computer Science education}

As just discussed, Computer Science (CS) has been highlighted in a number of recent reports. Shadbolt (2015) considered CS to have the worst record for graduate employability, and Gordon (2016) explored some of the issues around attainment and retention. This extended earlier work by Woodfield (2014) where Computer Science was identified as being the second worst subject for attainment (students achieving a good degree), and the worst overall subject in terms of students leaving with a lower or no award than that originally applied for. Some of the issues that Computer Science faces are that:

- It has become a popular subject with high student uptake and large cohorts;

- A mismatch between prior knowledge, expectations of the subject, and the actual technical requirements;

- Issues around student engagement and sense of community within their studies.

There is some evidence about certain characteristics within the cohort: procrastination and student syndrome; poor organisation; a highly uneven gender balance; high proportion of students on the autistic spectrum. The above issues and these characteristics can be particularly acute when it comes to assessment practice in the subject: whilst this does vary, some form of assessed coursework typically makes up a large part of both courses and degree programmes. Since successful coursework is often dependent on student organisation and regular and routine engagement, there is a potential conflict with the nature of many students. Whilst students can sometimes pass exams through last minute cramming, for coursework a failure to organise it sufficiently early can mean it cannot 
be recovered. Moreover, the scheduling of coursework can reduce the time available for study and assessment, with deadlines coming earlier than exam schedules so terms and semesters become curtailed.

\section{Flexible and Technological Solutions}

A curriculum that allows for flexibility, along with technologies to enable this, can address some of the issues within both STEM and Computer Science. The focus here remains Computer Science, though many are relevant to a wide range of disciplines, especially as programming has become core to many other science subjects.

\section{Technologies that enable flexibility}

Interactive tutorials and learning resources (reusable learning objects) can allow students to experience material in ways that can be learnt at a pace that suits them, with the opportunity to repeat content. Suitable progress assessments can assist in personalising this to ensure they have a sufficient grasp and evidence of engagement. Being web based, this clearly enables choice in where learning happens. Potentially, having a range of resources covering a particular topic with different learning styles can enable choice in the mode. Simply recording lectures can allow review of a session, and allow students who are not there to see it in their own time, but the choices are more limited ones, since there is no opportunity for interaction, or to ask live questions, nor for a variety of delivery approaches to support different modes of learning. Of course, a recorded lecture can be delivered and supported with a real time opportunity for Q\&A, or asynchronous forums. This example illustrates how different forms of teaching can be positioned in the 3-dimensions of flexibility.

Assessment is a particular issue for higher education, as assessment increasingly becomes the driver for student behaviour (Gibbs, 2006), yet increasingly problematic as cohort sizes increase: assessment and feedback are commonly the weak factor in National Student Surveys (Bell and Brooks, 2016), across departments and disciplines. Computer based assessment with multiple choice, short answer, numerical and symbolic answers can enable direct assessment of knowledge and application, and implicit assessment of other attributes. Adaptive testing, where the system probes understanding based on a knowledge and skills network, offers a way to personalise the computerised test, much as a human would probe a student in a viva.

Examples of other technologies to support flexibility in learning and assessment are interactive tutorials and adaptive testing and learning analytics (where these latter may be provide within a VLE or through some other external learning tool).

For Computer Science in particular, code evaluation and profiling tools and code management and code plagiarism tools can all be useful - and authentic - approaches to assist in assessing and providing feedback on practical coursework.

\section{Flexible Pedagogical Solutions}

Whilst the previous section described some examples of how technology can offer some solutions, the use of these requires appropriate pedagogical approaches. Flexibility does not mean everything need be chosen, but for some aspects, to meet learning outcomes students must do certain activities and achieve certain results. Also, the concerns around attainment and retention mean some activities and approaches become essential. In that context, planning teaching and assessment becomes a balance between how to address these points, whilst allowing some student choice. Some examples of how to manage this follow.

\section{Teamwork and developing a community}

One approach to address dropout rates and improve engagement with material is to utilise team work (Thomas, 2002). Team work provides a context for students to develop useful transferrable skills, whilst the team dynamic can improve engagement since the team-mates motivate one-another to work. This may not create friendship groups, but can promote community and opportunities for students to share and develop their learning. Suitable groupware technologies - institutional or freely available - naturally allow students a lot of choice in how they manage and contribute to these activities. Peer assessment 
of contributions to the work can make such flexible activity acceptable as students appreciate the impact of their own choices.

\section{Flexible Assessment}

Assessment can be a key factor in assisting students in deciding what to work on and how much effort to apply (Gibbs, 2006). Tests and exams can be good check points on student knowledge and engagement, but a traditional one-off exam is not flexible in either timing, location or type of learning. One approach that offers a little more choice is to allow students multiple attempts over a prolonged period. A simple MCQ format is not sufficient, as students may simply use trial and error. One approach the author has used is an adaptive test with feedback on topics that need developing. A similar model utilises a practice or diagnostic test paired with a test that students take when they feel ready. Such flexibility does not always fit well with university regulations nor some expectations of what assessment is.

\section{Conclusions}

Flexible pedagogy is not a silver bullet to solve all the issues with Higher Education, in STEM or Computer Science in particular. But it can offer some improvements and enhance the student experience. Existing systems and teaching can already enable choices in the three-dimensions of flexible learning; the barrier here can be staff and institutional intransigence. However, new developments and emerging technologies mean that there are new and exciting opportunities. Computer Science can offer solutions, as well as being a good focus for their application, given the particular characteristics and issues that raise existing concerns about employability, success and completion.

\section{References}

Altbach, P.G., Reisberg, L. \& Rumbley, L.E., (2009). Trends in global higher education: Tracking an academic revolution.

Bell, A.R. \& Brooks, C., (2016). What Makes Students Satisfied? A Discussion and Analysis of the UK's National Student Survey. A Discussion and Analysis of the UK's National Student Survey (April 22, 2016).
Cassidy, S., (2016). Virtual Learning Environments as mediating factors in student satisfaction with teaching and learning in Higher Education. Journal of Curriculum and Teaching, 5(1), p.p113. doi:10.5430/jct.v5n1p113

Gibbs, G., (2006). How assessment frames student learning. Innovative assessment in higher education, p.23.

Gordon, N., (2014). Flexible Pedagogies: technology-enhanced learning. From the report series Flexible Pedagogies: Preparing for the Future. The Higher Education Academy, January. Online at: http://www.heacademy.ac.uk/resources/detail/ flexiblelearning/flexiblepedagogies/tech enha nced learning/main report [Accessed 30 Sept 2016].

Gordon, N., (2015). Issues in retention and attainment in Computer Science. The Higher Education Academy, March. Online at: https://www.heacademy.ac.uk/resource/issue s-retention-and-attainment-computer-science [Accessed 30 Sept 2016].

HEFCE (2015) Graduate employment and accreditation in STEM. [Online]. Available at http://www.hefce.ac.uk/kess/gradstemreview/ [Accessed 20 Aug 2016].

Higher Education Academy (2013) Flexible Learning. [Online]. Available at: http://www.heacademy.ac.uk/flexible-learning [Accessed 25 July 2013].

O'Byrne, W.I. \& Pytash, K.E., (2015). Hybrid and Blended Learning. Journal of Adolescent \& Adult Literacy, 59(2), pp.137-140. doi: 10.1002/jaal.463

Pathak, V. \& Pathak, K., (2010). Reconfiguring the higher education value chain. Management in Education, 24(4), pp.166-171. doi: 10.1177/0892020610376791

Sarrab, M., Elgamel, L. and Aldabbas, H., 2012. Mobile learning (m-learning) and educational environments. International journal of distributed and parallel systems, 3(4), p.31.

Shadbolt, N. (2015) Unemployment among computer science graduates - what does the 
Flexible Learning in Computer Science

data say? [Internet]. Available from: http://blog.hefce.ac.uk/2015/07/08/unemploym ent-among-computer-science-graduateswhat-does-the-data-sayl [Accessed 7 January 2016].

Thomas, L. (2002) Student retention in higher education: the role of institutional habitus. Journal Educational Policy, 17(4), pp. 423-442. DOI 10.1080/02680930210140257

Universities UK, 2016. Student experience: measuring expectations and outcomes.

Verkroost, M.J., Meijerink, L., Lintsen, H. \& Veen, W., (2008). Finding a balance in dimensions of blended learning. International Journal on ELearning, 7(3), p.499.

Wen, L., Brayshaw, M. \& Gordon, N., (2012). Personalized content provision for virtual learning environments via the semantic web. Innovation in Teaching and Learning in Information and Computer Sciences, 11(1), pp.14-26.

Woodfield, R. (2014) Undergraduate Retention and Attainment Across the Disciplines [Internet]. Available from: https://www.heacademy.ac.uk/node/10293 [Accessed 15 June 2015] 